\title{
\begin{tabular}{|l|l|} 
IV Simpósio Paranaense de Modelagem, & Artigo: \\
Simulaçãoe Controle de Processos & $\mathbf{3 2}$ \\
ISSN : 1984-7521 & Páginas: $\mathbf{2 3 3}$ - 240
\end{tabular}
}

\section{Preliminary analysis for the implementation of a data acquisition system for the monitoring of vertical structures of telecommunications stations}

\author{
André Murilo Dias de Souza, Eugênia Leandro Almeida ${ }^{*}$, Wagner André dos Santos Conceição and \\ Cid Marcos Andrade
}

\author{
State University of Maringá Maringá - Brazil \\ E-mail: eugenia-almeida@ hotmail.com
}

\begin{abstract}
The purpose of this work was to perform a preliminary analysis of a benchmarking data acquisition system capable of collecting data to assist the monitoring of vertical structures of telecommunications stations, in order to make this information available to the management center of networks.
\end{abstract}

Keywords: Acquisition of data, telecommunications, vertical structures.

\section{Introduction}

In the current context, there is an increasing demand for data transfer rates, driven by increased voice, data and video traffic. Thus, we have experienced great advances in communications networks, related in their vast majority to the optimization of networks through the modernization of configurations, expansions and deployments of new technologies. In the search to meet these expectations, from a physical point of view, it is necessary to transform the infrastructure in these telecommunications stations, so that they are able to receive the new equipment and radiating systems responsible for these technological advances [1].

Migration of the analogue-to-digital television transmission system can be cited as a process of migration and technological advancement. This system seeks to optimize the use of the frequency spectrum, as well as to enable the implementation of the 4G (LTE) system. Other projects to be implemented in telecommunication stations, such as microwave radio links and radiating systems of different configurations.

In the last years the telecommunication market has been adopting in its stations the model of sharing and leasing of structure. The need for changes through technological advances, has increased accordingly, installation activities. These activities are generally carried out without adequate follow-up of pre-verification procedures, acceptance and maintenance of modified structures.

Frequently, occurrences of failures in these operating systems are reported. These failures are directly related to structural fatigue, damage caused due to the action of the wind, causing problems, such as, collapses in vertical structures, 
interferences in the signals, etc.

In this way, the work has the objective of developing a system of data acquisition, in scale of bench, with the purpose of simulating a system can be used as an instrument of assistance in the procedures of operations and maintenance of vertical structures of telecommunication stations.

\section{Materials and methods}

Aiming to help processes for the implantation of new digital radio links, procedures for preventive and corrective and predictive maintenance and operation [12], the system was built using sensors integrated with a microprocessor, in charge of capturing temperature and humidity data from the air, structural vibrations, wind direction and velocity.

The signals received by the sensors are transmitted to the microprocessor through electronic coupling circuits consisting of association of resistors and cabling provided with insulation for electromagnetic shielding. A computer program was developed to perform tasks of reading the data, handling and integrating the sensors.

\subsection{Principle of operation}

The system was designed to minimize the size of the system due to the fixation site (vertical stations) and to produce the smallest possible exposure to wind, with efficient geometry and aerodynamics.

The system was originally designed to be fed with available power from the station, however, it was considered the possibility of using alternative sources such as batteries, photovoltaic system among other possibilities.

The predicted technique suggests the use of the system as an auxiliary element of data collection, comparison and decision making according to the profile of the monitored structure. The system consists of wind speed sensor, wind direction indicator sensor, structural vibration sensor, temperature and humidity sensor, concentrator and computer program. Figure 1 represents the flowchart of the proposed. 


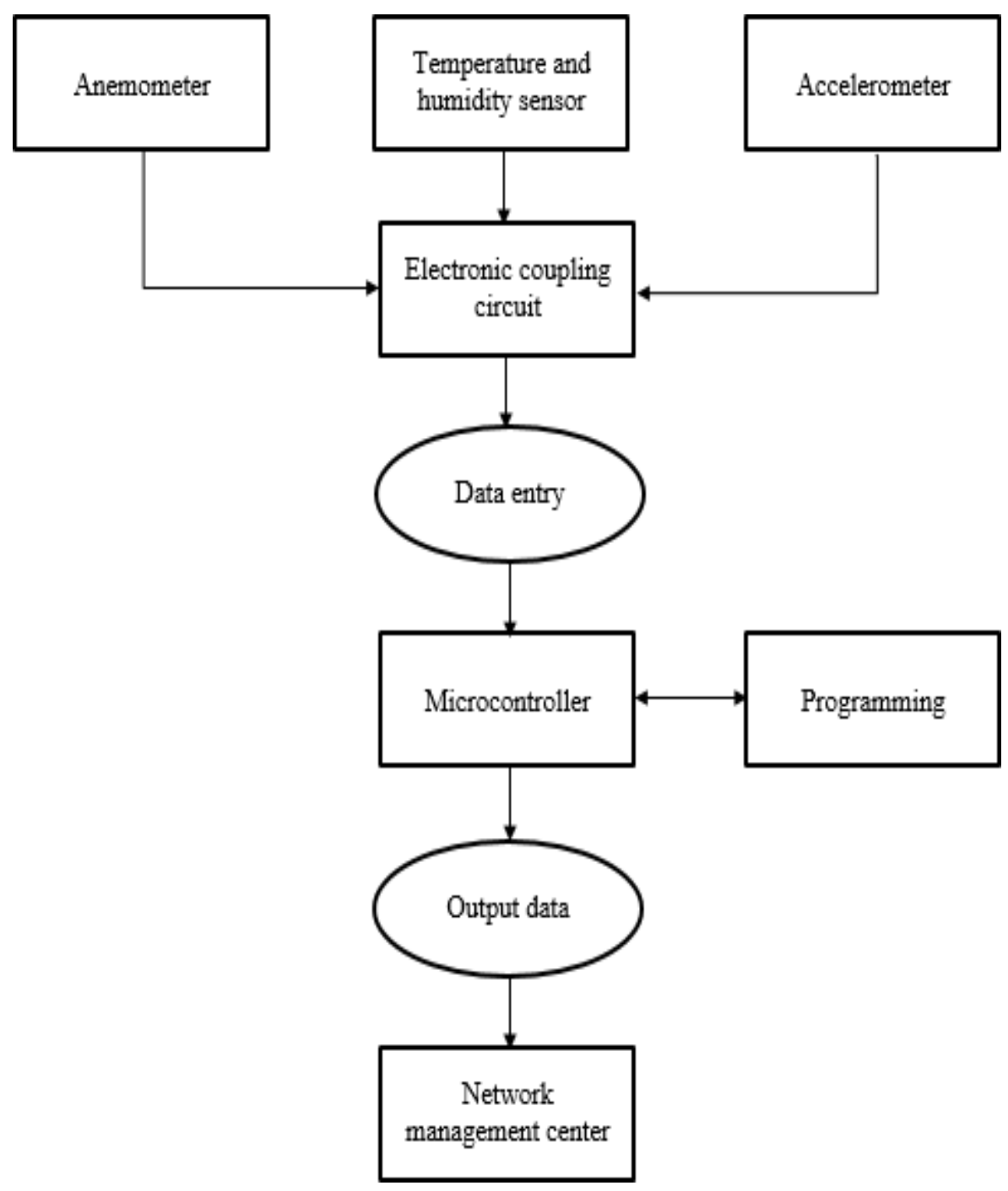

Figure 1: Simplified flowchart of the proposed system

The data provided by the anemometer are used in the decision by anticipating re-tightening, reinforcement or repair of the structure, in keeping the wind record report of the structure, for use of local community interest in activities such as agriculture, security, aviation and sports .

Vibrations in the structure can be interpreted by means of the variations detected by the accelerometer to allow considerations about factors influencing them, such as the possibility of loose screws, antennas, supports or other colliding parts. The possibility of fatigue, overload or pathology in the structure may arise on occasions where abnormal vibrations are recorded, such as when winds do not present sufficient velocity to justify such patterns, according to the installed exposure area.

In addition to the system, the temperature and humidity sensor DHT11 was added to provide future studies on the influence of these factors on vertical structures, such as oxidation and failure in galvanization, since they have a strategic geographical installation.

It should be noted that the data provided by the anemometer and the accelerometer contained in the system can axillary in the identifications climatic phenomena, such as earthquakes, cyclones, tornados, hurricanes and typhoons. 


\subsection{Wind speed sensor}

Wind speed determination was performed using a WRF brand anemometer integrated into the system. The WRF anemometer has support and sensors built in aluminum, with sealed bearing axis and therefore low maintenance $[2,3,4]$.

The pickups have $75 \mathrm{~mm}$ diameter, the holding bracket $260 \mathrm{~mm}$ long and the total diameter of the sensor $295 \mathrm{~mm}$. In this way, the dimensions and fixation systems of the sensor are compatible with the spacings commonly available in the structures of the stations for anchoring systems such as antennas and other network elements.

This sensor is resistant to strong winds with speeds of up to 150 kilometers per hour and with long durability.

The anemometer is built with Reed Switch / magnet, where at each rotation the contact is closed and then the signal is supplied. Figure 2 shows the construction of the WRF anemometer.

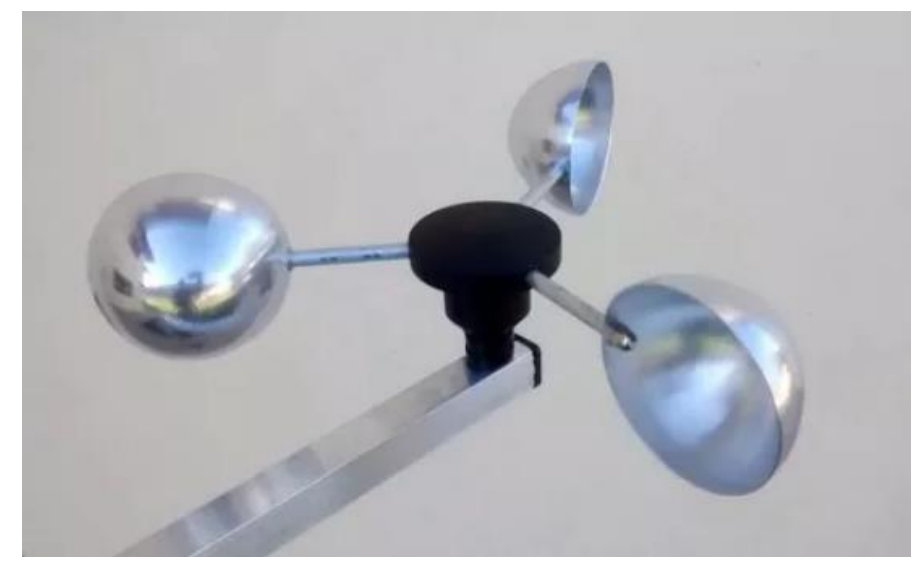

Figure 2: Anemometer WRF

\subsection{Wind direction indicator sensor}

The Anemoscope WRF, similar to the anemometer, is weather protected, constructed with an aluminum rod, with a $350 \mathrm{~mm}$ indicator axis and a $250 \mathrm{~mm}$ support. Contains mass of 350 grams and the wind direction indicator has resistive sensor sealed with $360^{\circ}$ rotation.

The original resolution is $45{ }^{\circ}$, taking direction readings at 0/45/90/135/180/225/270/315 ${ }^{\circ}$, ie North (N), South (S), East (L), West ( O) and the Northeast (NE), Southeast (SE), Southwest (SO) and Northwest (NO) collateral points. 
The principle of operation is based on the fixation of 08 Reed Switches around the central axis, with resistors coupled in an equidistant way, in order to allow the reading of electrical resistance equivalent to the positioning of the rod, thus determining the direction of the wind . The choice of this device is achieved by presenting the outstanding characteristics and low economic cost. Figure 3 shows the construction of the anemoscope WRF.

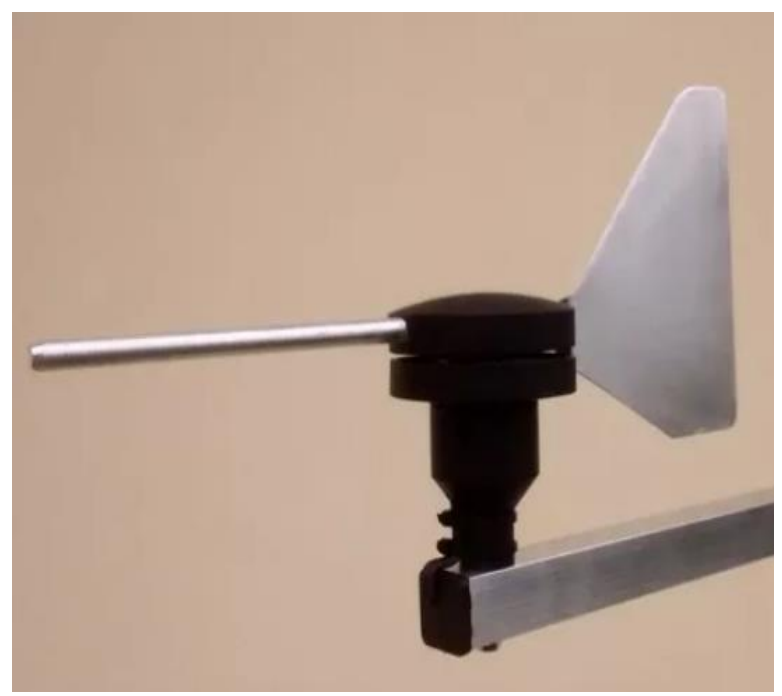

Figura 3: Construção do anemoscópio WRF

\subsection{Structural vibration sensor}

In order to measure the vibration intensity in the structures, the accelerometer ADXL345 was used, associated to a methodology of comparison between captured signals.

The accelerometer is a device that determines the acceleration of an object in relation to gravity. Reading the three axes at different times allows detection of movement or impact caused by dynamic acceleration. According to the manufacturer's manual the ADXL345 allows readings between $\pm 2 \mathrm{~g}$ to $\pm 16 \mathrm{~g}$, with high resolution less than $1.0^{\circ}$. Figure 4 shows an accelerometer ADXL345.

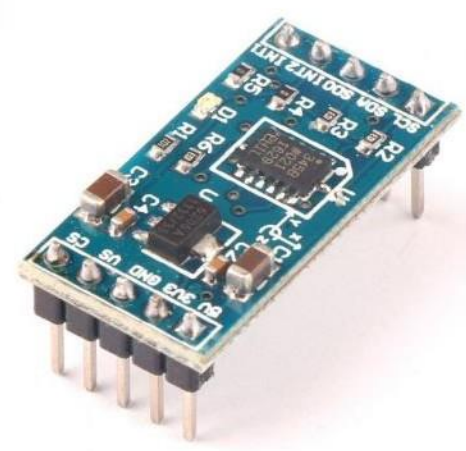

Figure 4: Accelerometer ADXL345 [13] 


\subsection{Temperature and humidity sensor}

The sensor DHT11 is a sensor that includes a single component, a moisture meter and a temperature measurement device. The protocol used for the data transfer allows the sending in a single wire of bus, with format of the data according to the ordering in 40 bits as below:

Data format: 8 data bits for the whole part of the humidity measurement, 8 data bits for the decimal part of the humidity measurement, 8 data bits for the whole part of the temperature measurement, 8 data bits for part decimal of temperature and 8bits referring to check sum, totalizing the 40 bits. Figure 5 shows the sensor temperature and humidity sensor DHT11.

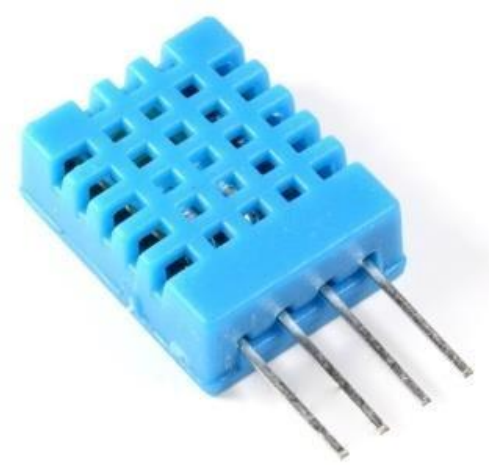

Figure 5: Temperature and humidity sensor DTH11

\subsection{Concentrador}

The system has connections through a free hardware electronic prototyping platform, designed with an Atmel microcontroller that uses standard $\mathrm{C}$ and / or $\mathrm{C}++$ based programming language.

This platform, commercially known as Arduíno Uno was connected to the sensors by means of an electronic coupling circuit, and the signal processing takes place according to the routines of a specific computational program developed for management. The central microcontroller has 32 kilobytes of flash memory, 2 kilobytes of RAM and operates at a frequency of 16 megahertz.

\subsection{Computer program}

The computational program designed to interact between the sensors and the acquisition system was designed in such a way as to maximize processing and promote stability of the system, including possible restarts for possible power failures without being erased from its source.

The tasks performed by the program are basically related to initialization of sensor libraries, repetition loop executions, variable values loading, counts, timings, and comparisons. Finally, information on the serial port is made available to enable integration with other systems, generation of graphs, reports, alarms and actuators, as well as other activities, considering the interactivity enabled between the operator and the management center. 


\section{Results and discussion}

The system performance evaluation was performed initially on a bench using a prototype. Following, in real scenario, with the installation of the system in a freestanding tower of a television station of the city of Maringá-PR.

During the initial phase of the project, it was considered only the velocity record of the winds on the structure. The results obtained during the bench tests indicated a reasonable acceptance of the system.

Intermediate techniques were experimented and became useful for the improvement of the system, with experiments using different sensors of low economic cost and found with ease in the market [8].

One of the analyzes carried out was evaluated the sensor DHT11, in order to evaluate the presence of winds through humidity variation records. Figure 6 presents the model used in this analysis.

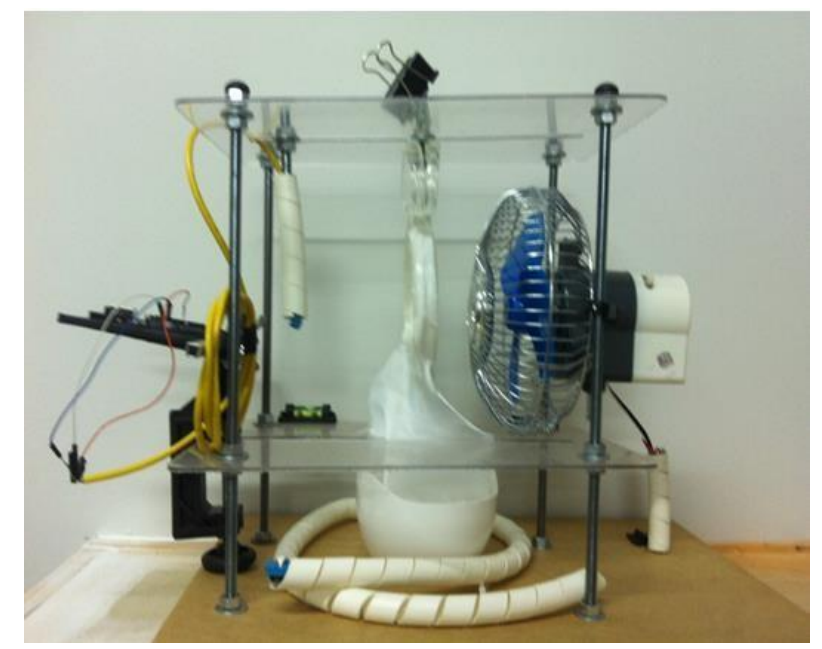

Figure 6: Model built for performance assessment of DHT11 bench scale technique

During bench testing benchmarks did not verify inconsistency data records greater than the tolerance allowed by system components in agreement with data provided by the manufacturers.

\section{Conclusion}

From the preliminary analysis it is concluded that the technique of comparing the signals collected through the wind velocity sensors and system vibrations allows to provide a particular signature of the state of equilibrium of the monitored structure, enabling important decisions such as the anticipation of maintenance routines.

Hypotheses such as detections of large structural vibrations in situations where the measured intensity of the recorded winds were small suggest signs of structural failure residing in the installation due to the disproportion between them. 
Similarly, the record of wind intensities higher than the maximum predicted in the structural design can be considered as a preponderant factor to anticipate the reestablishment of the structure, to approve a structural reinforcement and to avoid a collapse and accidents with victims. On the other hand, the possibility of providing local meteorological data can offer great benefit to boost activities such as agriculture, security, aviation among other community interests and even new business opportunity for the holder.

In this regard, it is worth considering the possibility of performing tests containing other specifications of sensors and more powerful concentrator platforms aimed at processing even more efficient for this technique. This reflection is due to the fact that the election of the current components of the system, although presenting satisfactory partial performance, are components of low cost and of easy acquisition as previously illustrated.

\section{References}

[1] ANATEL - Agência Nacional de Telecomunicações, Resolução No 625, de 11 de Novembro de 2013, Diário Oficial da União. Diário Oficial da União, Brasília, 2013.

[2] Ribeiro, J. A. J. Propagação das ondas eletromagnéticas, 2004.

[3] Martín. Patricia, Experimental study of the effects of dish antenas on the Wind loading of telecommunication towers. Journal of Wind enfineering and industrial aerodynamics, pp. 40-47, 2016.

[4] Messer, H.; Zinevich, A.; Alpert P. Environmental sensor networks using existing wireless communication systems for rainfall and wind velocity measurements. IEEE Ins. Measur. Vol. 15(2), pp. 32-38, 2012.

[5] ABNT - Associação brasileira de normas técnicas. NBR 6123: forças devidas ao vento em edificações. Rio de Janeiro, 1988.

[6] Vaz. Á. Procedimento para Análise Estática das Ações do Vento em Torres Metálicas Autoportantes Treliçadas em Perfis de Cantoneiras Revista Especialize. IPOG, 2015.

[7] Blessmann, J. Acidentes causados pelo vento. Editora da Universidade Federal do Rio Grande do Sul, UFRGS, 2001.

[8] Gonzáles, R. D. Desenvolvimento de um protótipo analisador de vibração de baixo custo para uso em manutenção preditiva. Universidade Federal de Santa Catarina - UFSC, 2014.

\section{Acknowledgments}

The authors would like to thank Coordenação de Aperfeiçoamento de Pessoal de Nível Superior (CAPES) for the financial support. 